\title{
PAPER
}

Check for updates

Cite this: New J. Chem., 2019, 43,12641

\section{Functional bisphosphonate synthesis for the development of new anti-resorption bone drug candidates $\dagger$}

\author{
Enrica Bortolamiol, Andrea Chiminazzo, Laura Sperni, Giuseppe Borsato, \\ Fabrizio Fabris and Alessandro Scarso (iD *
}

\begin{abstract}
Herein we present the synthesis of $\beta$-mono and $\beta$-bis-substituted vinylidenebisphosphonate esters bearing a carboxylic ester moiety to be used as building blocks for further functionalizations. Reactions of these new bisphosphonate scaffolds through hydrogenation of the unsaturated $\mathrm{C}=\mathrm{C}$ bond and through metal mediated addition of aryl boronic acids and indoles provide a wide range of new bisphosphonate products as potential leads to contrast osteoporosis.
\end{abstract}

Received 14th May 2019, Accepted 16th July 2019

DOI: 10.1039/c9nj02504a

rsc.li/njc

$$
{ }_{\mathrm{HO}_{\mathrm{R}_{1}}^{\prime \prime}}^{\mathrm{O} \mathrm{R}_{2}^{\prime}}
$$

bisphosphonic acid

pyrophosphoric acid phosphonic acid moieties connected through a methylene linker whose chemical similarity to hydroxyapatite, a major mineral component of bones, is responsible for their specific bone targeting properties ${ }^{1}$ and because of this they have been used for decades in medicinal chemistry ${ }^{2}$ for the treatment of bone disorders such as hypocalcemia and osteoporosis.

The close correlation between their chemical structures $\left(\mathrm{R}_{1}\right.$ and $\mathrm{R}_{2}$ groups shown in Scheme 1$)$ and the biological activity is still a highly debated topic; ${ }^{3,4}$ in particular it has been recognized that their cellular activity is related to their ability to inhibit specific enzymes such as farnesyl diphosphate synthase (FPPS), geranylgeranyl diphosphate synthase (GGPPS) ${ }^{5,6}$ and other ones ${ }^{7}$ present in osteoclasts which are the cells deputed for bone resorption. As long as their chemical structure is concerned, the presence of a hydroxyl group at position $\mathrm{R}_{1}$ of BP (Scheme 1) enhances the affinity for hydroxyapatite in bones. The presence of $\mathrm{N}$ containing residues on $\mathrm{R}_{2}$ is very important as evidenced by the structures of the commercially available alendronic and zoledronic acids clinically used to contrast osteoporosis (Scheme 1). The combination of $\mathrm{N}$ atoms in the side chain together with a long alkyl chain on $\mathrm{R}_{2}$ provide even more efficient BPs to contrast bone resorption. ${ }^{5}$ Other therapeutic effects attributed to specific BPs range from anticancer activities, ${ }^{8}$ to antibacterial and anti-malarial properties. ${ }^{9}$

Dipartimento di Scienze Molecolari e Nanosistemi, Università Ca' Foscari di Venezia, via Torino 155, 30172, Mestre, Venezia VE, Italy. E-mail: alesca@unive.it; Fax: +39-041-234-8517; Tel: +39-041-234-8569

$\dagger$ Electronic supplementary information (ESI) available: Full experimental procedures and characterization spectra. See DOI: 10.1039/c9nj02504a

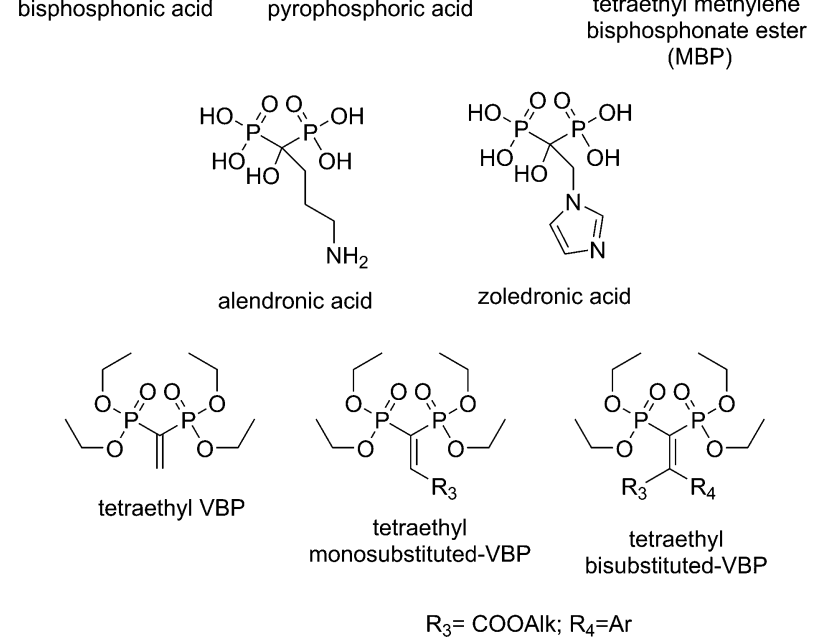

Scheme 1 Chemical structure of a generic bisphosphonic acid, pyrophosphoric acid, tetraethyl methylene bisphosphonate ester (MBP), alendronic and zoledronic acids, vinylidenebisphosphonate tetraethyl ester (VBP) and related compounds with one or two substituents at the $\beta$ position.

The chemical structure of the currently available BPs is rather limited and the search for more potent and better tolerated N containing BPs is a highly desirable topic. It is also worth emphasizing that, despite the importance of chiral drugs which are nowadays a landmark in drug discovery, the development of chiral BPs and the investigation of their biological activity are still rather unexplored topics ${ }^{10}$ which deserve further investigation. ${ }^{11}$ For this purpose, the development of new prochiral BP scaffolds to widen the structural variability of BPs is highly desirable. 
The synthesis of BPs bearing the $\mathrm{OH}$ moiety on $\mathrm{R}_{1}$ is usually accomplished starting from a carboxylic acid ${ }^{12,13}$ or an acyl chloride derivative; ${ }^{14}$ conversely BPs lacking the $\mathrm{OH}$ moiety on $\mathrm{R}_{\mathbf{1}}$ are more commonly prepared by Michael addition of nucleophiles to vinylidenebisphosphonate tetraethylester $(\mathrm{VBP})^{15}$ as a typical electrophilic building block (Scheme 1). Addition reactions to the electron poor $\mathrm{C}=\mathrm{C}$ of $\mathrm{VBP}$ enabled the preparation of several classes of BPs containing thio-ether units, $^{16}$ heterocycle $^{17}$ steroid conjugates and cycloaddition derivatives through reaction with dienes ${ }^{18,19}$ and nitrones. ${ }^{20,21}$ Recently, metal catalyzed addition of indoles and boronic acids to VBP led to a further enrichment of the structural variability of BPs. ${ }^{22,23}$

In continuation of our effort in the field, ${ }^{24}$ we focused our attention on the development of new unsaturated BP precursors; ${ }^{25}$ in particular herein we describe the synthesis of $\beta$-mono-substituted and $\beta$-bis-substituted VBP prochiral precursors bearing a carboxylic ester unit in the side chain $\mathrm{R}_{3}$ (Scheme 1). Examples of disubstituted VBP precursors are very limited in the literature, and in particular worth mentioning are the structures bearing two identical substituents at the $\beta$-position as shown in Scheme $2 \mathrm{~A} .^{26,27}$

Abdou and co-workers recently reported a one-pot procedure to obtain a series of branched N-heterocyclic-substituted VBPs (Scheme 2B). ${ }^{28}$ Another example was reported using a copperpromoted domino condensation/S-arylation/heterocyclization process for the synthesis of a series of $2-C$-substituted benzothiazoles containing gem-BPs (Scheme 2C). ${ }^{29}$ In the latter two examples both substituents at the vinyl position are part of the same heterocyclic ring. Upon reaction of MBP with $N_{1}$ - and $N_{3}$-allyl-2-thiouracils under phase-transfer catalysis conditions, the products reported in Scheme $2 \mathrm{D}$ and $\mathrm{E}$ were obtained. ${ }^{30} \mathrm{~A}$ useful synthetic route for the formation of enamino keto esters which use nitriles and ethyl acetoacetate has been reported recently by Pei and collaborators (Scheme $2 \mathrm{~F}$ ). ${ }^{31}$
A)<smiles>CCOP(=O)(OCC)C(=C(SC)SC)P(=O)(OCC)OCC</smiles>

B)<smiles>[R]C1=NC(=C(P(=O)(OCC)OCC)P(=O)(OCC)OCC)NN=C1C</smiles>

C)

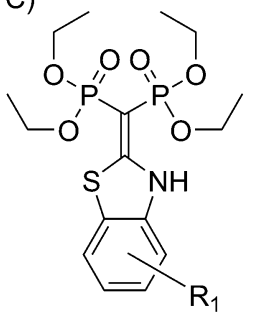

D)<smiles>CCOP(=O)(OCC)C(=C(CC)n1c(=O)cc[nH]c1=S)P(=O)(OCC)OCC</smiles>

E)<smiles>CCOP(=O)(OCC)C(=C(CC)n1ccc(=O)[nH]c1=S)P(=O)(OCC)OCC</smiles>

F)<smiles>CCOP(=O)(OCC)C(=C(N)c1ccccc1)P(=O)(OCC)OCC</smiles>

Scheme 2 Examples of bis-substituted VBP structures recently reported in the literature.

\section{Results and discussion}

Inspired by the recent publication reporting the reactivity of the benzylidene malonate intermediate with $\alpha$-keto ester reagents ${ }^{32}$ catalyzed by $\mathrm{TiCl}_{4}$, we decided to investigate the condensation of MBP with glyoxylate derivatives catalyzed by $\mathrm{TiCl}_{4}$ and $\mathrm{NEt}_{3}$ aiming at obtaining bis-substituted VBP precursors (Scheme 3) endowed with one aromatic and one ester substituent, of which the latter is useful for further functionalization.

\section{Synthesis of substituted VBP}

A solution of ethyl glyoxylate in toluene was used for the reaction with MBP mediated by TEA and $\mathrm{TiCl}_{4}$ (Scheme 4) leading to the formation of the corresponding condensation product in high yield. The latter was identified as ethyl-3,3bis(diethoxyphosphoryl)acrylate 1a, a new mono-substitutedVBP precursor bearing an ester substituent at the $\beta$-position, while the known mono-substituted-VBP precursor has exclusively aryl, alkenyl and alkyl moieties at the same position. ${ }^{33}$ The ${ }^{1} \mathrm{H}$ NMR spectrum of $\mathbf{1 a}$ was characterized by the presence of the resonance of the $\beta$-hydrogen at $7.43 \mathrm{ppm}$ as a doublet of doublets $(J=44.4,27.7 \mathrm{~Hz})$ due to the coupling with the two diastereotopic $\mathrm{P}$ atoms. Accordingly, the ${ }^{31} \mathrm{P}$ NMR spectrum showed two resonances at 13.01 and $9.22 \mathrm{ppm}$ with ${ }^{2} J_{\mathrm{P}-\mathrm{P}}$ of 42.2 Hz. The new substituted VBP derivative turned out to be stable at $0{ }^{\circ} \mathrm{C}$ for weeks.

Commercially available molecules structurally similar to ethyl phenylglyoxylate are methyl and ethyl pyruvates. The latter were tested under the above reported experimental conditions but unfortunately did not lead to any product formation probably because possible enolate species can be formed due to the presence of $\alpha$ hydrogen atoms in the $\alpha$-keto ester units that could be further involved in aldol condensation side-reactions. $t$-Butyl pyruvate and diethyl oxalate under the experimental conditions, as shown in Scheme 4, also failed to provide the corresponding desired product.

Spurred by the positive result observed with ethyl glyoxylate, we thus investigated a wide spectrum of commercially available

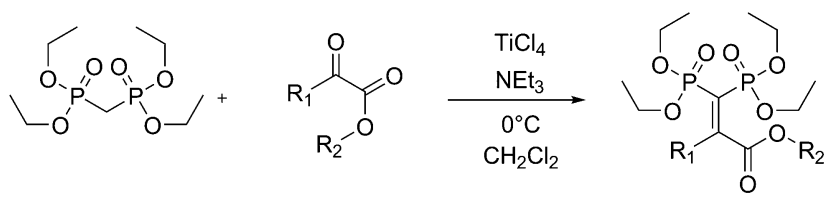

Scheme 3 Condensation reaction of glyoxylate derivatives with MBP catalyzed by $\mathrm{TiCl}_{4}$ and TEA.
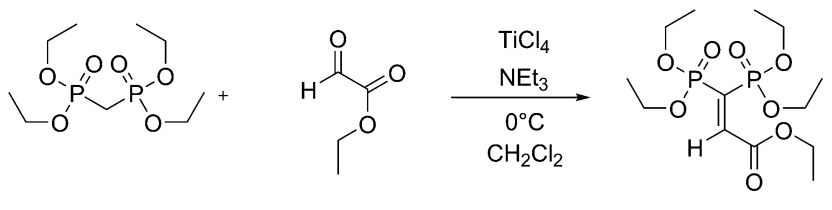

1a, $90 \%$

Scheme 4 Condensation reaction of ethyl glyoxylate catalyzed by $\mathrm{TiCl}_{4}$ and $\mathrm{NEt}_{3}$ with MBP forming the corresponding product $\mathbf{1 a}$. 
and synthetic $\alpha$-keto esters with different steric and electronic properties and characterized by the presence of sensitive functional groups to test the generality of the synthetic method. The obtained results are reported in Table 1. The reaction between MBP and ethyl phenylglyoxylate in the presence of TEA as organic base and $\mathrm{TiCl}_{4}$ as hard-Lewis acid led to the formation of the desired product $\mathbf{1 b}$ in $90 \%$ yield (Table 1 , entry 1 ).

The ${ }^{31} \mathrm{P}$ NMR spectrum showed the presence of two distinct resonances at 11.28 and $10.13 \mathrm{ppm}$ for the $\mathrm{P}$ atoms with a ${ }^{2} J_{\mathrm{P}-\mathrm{P}}$ coupling constant of $44.5 \mathrm{~Hz}$ (see the ESI $\dagger$ ). The ethoxy residues of the carboxylic ester and the two of the different phosphonic esters were all characterized by different chemical shifts both for the methylene and the methyl residues, as confirmed by the COSY spectrum of $\mathbf{1 b}$ (see the ESI $\dagger$ ). As expected, the use of methyl phenylglyoxylate led to the formation of the corresponding product with yield similar to that of the ethyl derivative (Table 1, entry 2).

The use of numerous aryl glyoxylates synthesized according to the procedures reported in the literature ${ }^{34,35}$ allowed us to study the scope of the reaction by varying the steric and electronic properties of the reagent. The presence of electrondonating groups on the aryl residues led to slightly lower yields compared to those bearing electron-withdrawing groups (Table 1 , entries 3-5). The reaction proved to be very sensitive to the steric properties of the reagent, and in fact the presence of substituents at the ortho position of the phenyl group led to a decrease in the reaction yield (Table 1, entries 4-6).

The presence of a halogen substituent such as chlorine at the ortho position of the phenyl ring turned out to be detrimental for the yield of the corresponding products (Table 1, entry 8). An electron-withdrawing group like nitro at the para position of the aromatic ring led to good yield of the corresponding product $\mathbf{1 k}$ (Table 1, entry 10) while other two aryl glyoxylate reagents bearing electron poor aryl units such as pentafluoro phenyl and pyridyl led to low and moderate yields of the corresponding products $\mathbf{1 j}$ and 11 (Table 1 entries 9 and 11).

\section{Hydrogenation of bis-substituted VBP products 1b-1}

In the literature several examples of hydrogenation reactions of phosphonate monosubstituted alkenes have been reported, ${ }^{36,37}$ most of which employ Pd supported on carbon as a catalyst. There are also examples of hydrogenation of double bonds substituted with phosphonate groups using sodium borohydride as a reducing reagent. ${ }^{38,39}$ We decided to investigate the use of $\mathrm{Pd} / \mathrm{C}$ as heterogeneous catalysts for the hydrogenation of some of the bis-substituted VBP products reported in Table 1 to obtain the corresponding racemic products $2 \mathbf{b}-\mathbf{l}$ (Scheme 5 and Table 2).

As long as the structure of the substrates is concerned, all the substrates led to the corresponding saturated hydrogenation product in quantitative yields, while the reaction on $1 \mathbf{k}$ led predominantly to the reduction also of the nitro group to the amino group as the main product (Table 2 , entry 10 product $2 \mathbf{k}^{\prime}$ ) with only $18 \%$ of $2 \mathbf{k}$ (Table 2 , entry 10 ). The structures of the two products $2 \mathbf{k}$ and $2 \mathbf{k}^{\prime}$ were confirmed by mass spectrometry analysis and the ${ }^{31} \mathrm{P}$ NMR spectra clearly showed

Table 1 Synthesis of bis-substituted VBP $\mathbf{1 b}-\mathbf{1 l}$<smiles>CCCOP(=O)(OCC)/C(=C(\OCC)C(=O)OCC)c1ccccc1C(=O)OCC</smiles>

2<smiles>COC(=O)C(=O)c1ccccc1</smiles>
3<smiles>CCOC(=O)c1ccc(OC)cc1</smiles>

4<smiles>CCOC(=O)c1ccccc1OC</smiles>
5<smiles>CCOC(=O)c1ccc(OC)cc1OC</smiles>
6<smiles>CCOC(=O)C(=O)c1ccccc1C</smiles>
7<smiles>CCOC(=O)C(=O)c1ccc(OC(F)(F)F)cc1C</smiles>
8<smiles>CCOC(=O)C(=O)c1ccccc1Cl</smiles>

1b<smiles>CCOP(=O)(OCC)C(=C(C(=O)OC)c1ccccc1)P(=O)(OCC)OCC</smiles>

1c<smiles>CCOC(=O)C(=C(P(=O)(OCC)OCC)P(=O)(OCC)OCC)c1ccc(OC)cc1</smiles>

73

58

63

60

64

84

列<smiles>CCOC(=O)C(=C(C(=O)OCC)P(=O)(OCC)OCC)P(=O)(OCC)OCC</smiles><smiles>CCOC(=O)C(=C(C(=O)OCC)P(=O)(OCC)OCC)P(=O)(OCC)OCC</smiles><smiles>CCOC(=O)C(=C(P(=O)(OCC)OCC)P(=O)(OCC)OCC)c1ccccc1C</smiles>

$1 \mathrm{~g}$<smiles>CCOC(=O)C(=C(P(=O)(OCC)OCC)P(=O)(OCC)OCC)c1ccc(OC(F)(F)F)cc1C</smiles>

1h<smiles>CCOC(=O)C(=C(P(=O)(OCC)OCC)P(=O)(OCC)OCC)c1ccccc1Cl</smiles>

8<smiles>C1CCC1</smiles> 
Table $2 \mathrm{Pd} / C$ catalyzed hydrogenation of bis-substituted VBP precursors<smiles>CCOC(=O)c1c(F)c(F)c(F)c(F)c1F</smiles><smiles>CCOC(=O)C(=C(P(=O)(OCC)OCC)P(=O)(OCC)OCC)c1c(F)c(F)c(F)c(F)c1F</smiles>

28

1

$1 b$

Bis-substituted VBP $\quad$ BP product<smiles>CCOC(=O)C(c1ccccc1)C(P(=O)(OCC)OCC)P(=O)(OCC)OCC</smiles>

$2 b$<smiles>CCOP(=O)(OCC)C(C(C(=O)OC)c1ccccc1)P(=O)(OCC)OCC</smiles>

92

$21 \mathrm{c}$

10<smiles>CCOC(=O)c1ccc([N+](=O)[O-])cc1</smiles>

11<smiles>CCOC(=O)C(=O)c1ccccn1</smiles><smiles>[Y]CCOP(=O)(OCC)C(=C(C(=O)OCC)P(=O)(OCC)OCC)c1ccc([N+](=O)[O-])cc1</smiles>

1

Reaction conditions: $1 \mathrm{mmol} \mathrm{MBP,} 1 \mathrm{mmol} \alpha$-keto esters, $4 \mathrm{mmol} \mathrm{NEt}_{3}$, $1 \mathrm{mmol} \mathrm{TiCl}_{4}, 25 \mathrm{~mL} \mathrm{CH}_{2} \mathrm{Cl}_{2}, 0{ }^{\circ} \mathrm{C}$. ${ }^{a}$ Isolated yield. The products were all obtained on hundred $\mathrm{mg}$ scale, purified by flash chromatography.<smiles>[R]OC(=O)C(=C(P(=O)(OCC)OCC)P(=O)(OCC)OCC)c1ccccc1</smiles>

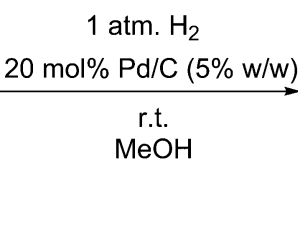

$\mathrm{R}_{1}=\mathrm{Me}, \mathrm{Et}$

Scheme $5 \mathrm{Pd} / \mathrm{C}$ catalyzed hydrogenation of Bi-substituted VBP precursors.

two different pairs of doublets downfield shifted with respect to the starting prochiral VBP attributed to the two reduced products.

Different from what is observed with the other substrates, the hydrogenation of $\mathbf{1 i}$ under identical experimental conditions not only led to the hydrogenation of the double bond but also to the hydro-dechlorination of the aromatic unit, leading to the formation of $\mathbf{2} \mathbf{b}$ as the main product while $2 \mathbf{i}$ was not obtained (Table 2, entry 8). As a typical example, in Fig. 1 are reported the ${ }^{1} \mathrm{H}$-NMR (A) and ${ }^{1} \mathrm{H}\left\{{ }^{31} \mathrm{P}\right\}$-NMR (B) spectra of 2e. In the latter spectrum the $\mathrm{H}-\mathrm{P}$ coupling is not observed, and this provides a simplification of the resonances of the $\alpha$ and $\beta$ protons that are characterized only by $\mathrm{H}-\mathrm{H}$ coupling with ${ }^{3} \mathrm{~J}$ of $9.8 \mathrm{~Hz}$. The ${ }^{31} \mathrm{P}$ $\left\{{ }^{1} \mathrm{H}\right\}$-NMR spectrum of $2 \mathrm{e}$ showed the presence of two doublets
$7 \quad \mathbf{1 h}$

$8 \quad 1 \mathrm{i}$

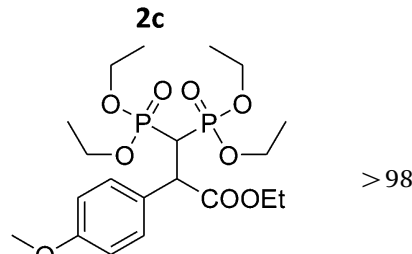

$>98$
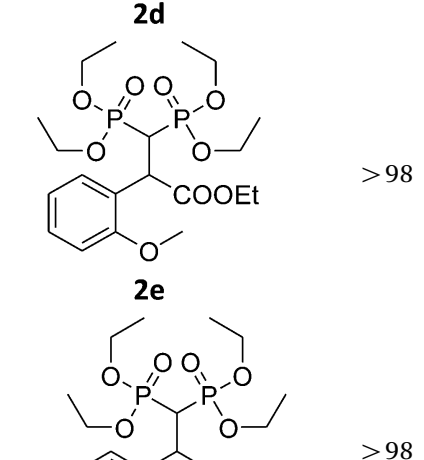<smiles>[Z17]Oc1cc(OC)ccc1C(C)C(=O)OCC</smiles>

$>98$<smiles>CCOC(=O)C(c1ccccc1C)C(P(=O)(OCC)OCC)P(=O)(OCC)OCC</smiles>

$2 \mathrm{~g}$<smiles>CC=CC(C[O+])C(P(=O)(OCC)OCC)P(=O)(OCC)OCC</smiles><smiles>CCOC(=O)c1ccc(OC(F)(F)F)cc1C</smiles>

$2 \mathrm{~h}$<smiles>CCOC(=O)C(c1ccccc1Cl)C(P(=O)(OCC)OCC)P(=O)(OCC)OCC</smiles>

$\mathbf{2 i}$ 
Table 2 (continued)

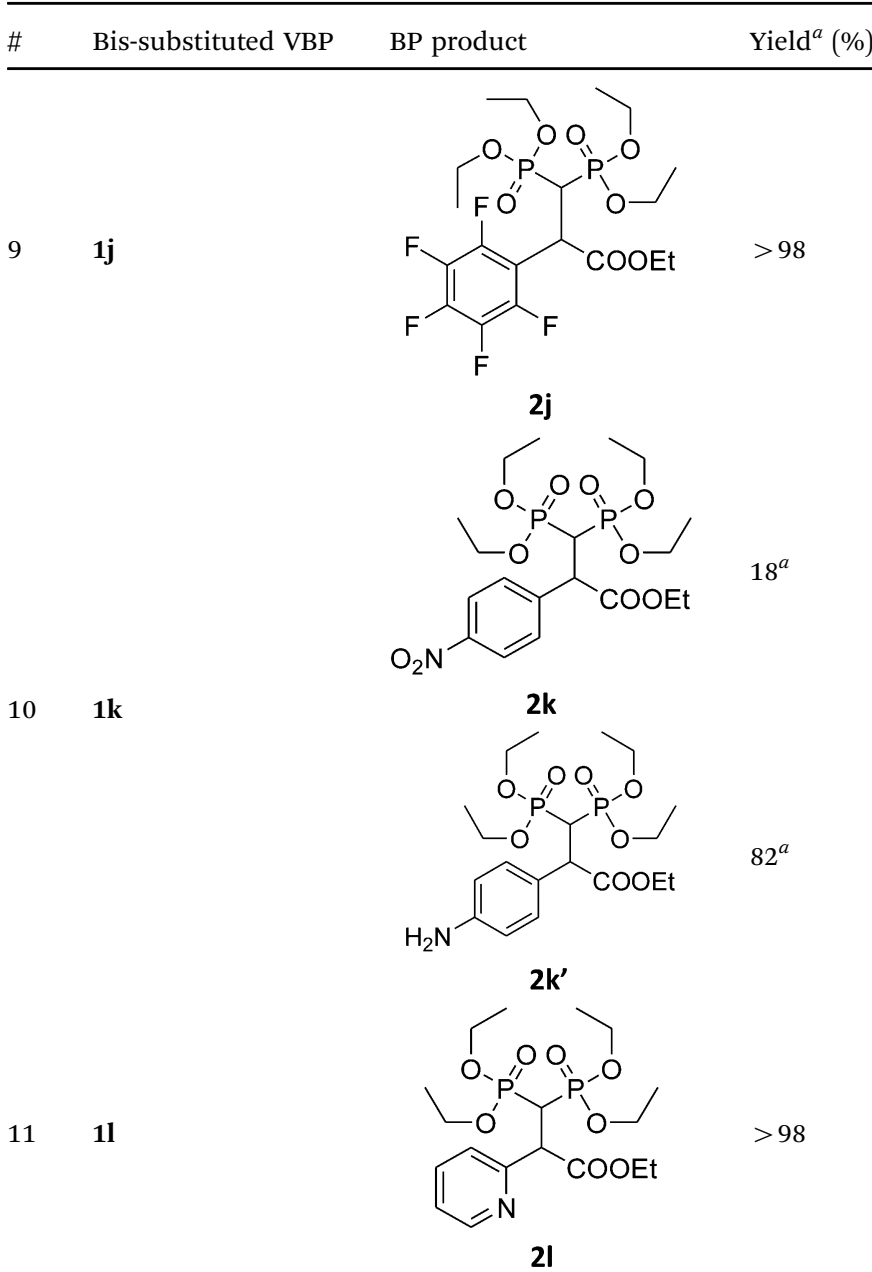

Reaction conditions: $1 \mathrm{mmol}$ of VBP, $20 \mathrm{~mol} \%$ of $5 \% \mathrm{w} / \mathrm{w} \mathrm{Pd} / \mathrm{C}, 1 \mathrm{~atm} \mathrm{H}_{2}$, $\mathrm{MeOH}$, r.t., $t=$ overnight. $^{a}$ Isolated yield.

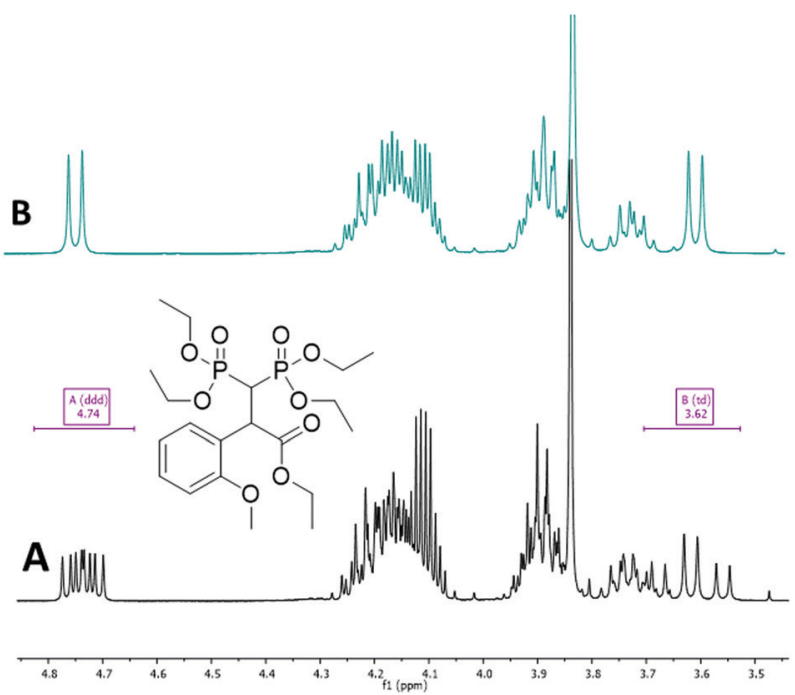

Fig. 1 (A) ${ }^{1} \mathrm{H}-\mathrm{NMR}$ and $(\mathrm{B}){ }^{1} \mathrm{H}\left\{{ }^{31} \mathrm{P}\right\}-\mathrm{NMR}$ of $\mathbf{2 e}$

downfield shifted with respect to $1 \mathrm{e}$ with a small coupling constant of $0.8 \mathrm{~Hz}$ (Fig. 2).

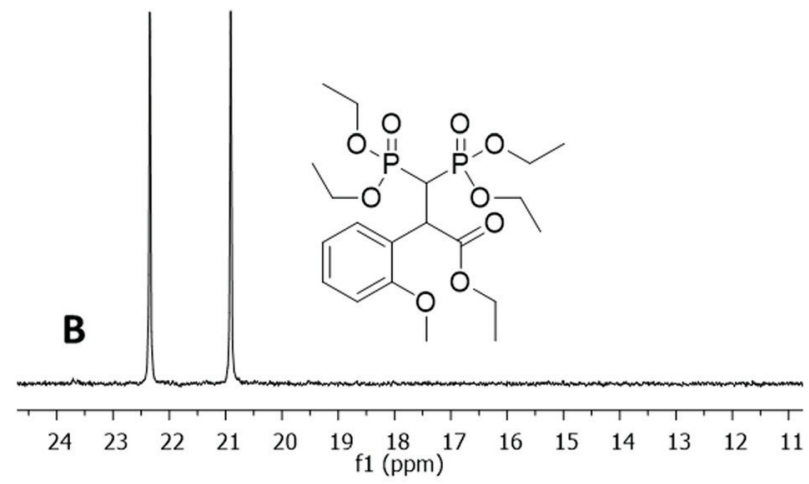

A
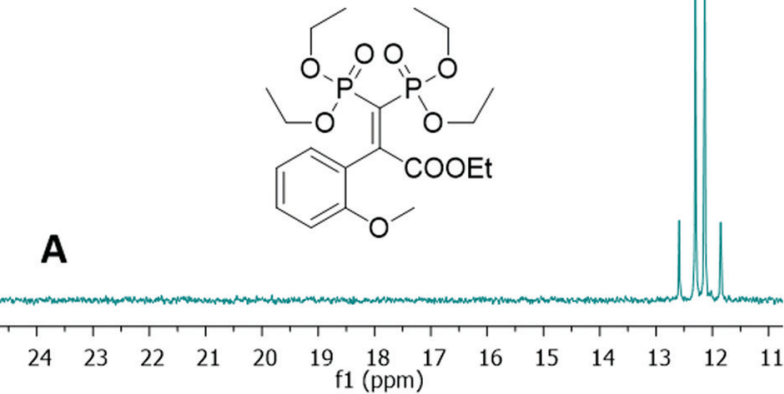

Fig. 2 (A) ${ }^{31} \mathrm{P}\left\{{ }^{1} \mathrm{H}\right\}-N M R$ of $2 \mathrm{e}$ and $(B){ }^{31} \mathrm{P}\left\{{ }^{1} \mathrm{H}\right\}-\mathrm{NMR}$ of $1 \mathrm{e}$

\section{Asymmetric hydrogenation of bis-substituted VBP}

$\mathrm{Rh}(\mathrm{I})$ complexes bearing chiral ligands appear to be the best choice for the catalytic asymmetric hydrogenation of olefin or $\alpha, \beta$-unsaturated compounds as demonstrated in the literature. ${ }^{40}$ As long as the stereoselective hydrogenation of alkenes bearing the phosphonate moiety is concerned, previous studies demonstrated that the best ligands were chiral phosphines. ${ }^{41}$

Substrate 1b was used for the stereoselective Rh(I) catalyzed hydrogenation screening a range of chiral enantiopure di-phosphine ligands. The use of $0.5 \mathrm{~mol} \%$ of (acetylacetonato)dicarbonylrhodium(I) coupled with $(S)$-BINAP or $(R)$-1-[( $S)$-2-(diphenylphosphino)ferrocenyl]-ethyldicyclohexylphosphine $((R)$-JOSIPHOS) with respect to $\mathbf{1 b}$ did not lead to any formation of the desired hydrogenation product at room temperature and 10 bar pressure of $\mathrm{H}_{2}$. The same catalytic systems under forced reaction conditions (50 bar and $50{ }^{\circ} \mathrm{C}$ ) led to the same results. These drastic reaction conditions were used also with a metal precursor chloro(1,5cyclooctadiene)rhodium(I) dimer without ligands showing that $\mathrm{Rh}(\mathrm{I})$ cannot catalyze the hydrogenation of the double bond of the bis-substituted BP precursor.

Metal catalysis was therefore abandoned, and other reducing agents were considered. We focused our attention on the use of $\mathrm{NaBH}_{4}$ in combination with enantiopure organocatalysts. In the absence of any organocatalyst, $\mathrm{NABH}_{4}$ hydrogenation of $\mathbf{1 b}$ resulted in the quantitative formation of saturated product $\mathbf{2 b}$.

The asymmetric version of the reaction was therefore performed with quinine-thiourea and quinidine-thiourea as organocatalysts ${ }^{42}$ which are commonly used H-bonding organocatalysts for Michael type addition reactions known to be active on phosphonate 
compounds ${ }^{43}$ and previously tested by our group for the stereoselective synthesis of chiral isatin containing BPs. ${ }^{24 c}$

The organocatalyzed hydrogenation of $\mathbf{1 b}$ led to quantitative yields of the hydrogenated product $\mathbf{2 b}$ but unfortunately, chiral HPLC analyses showed however no asymmetric induction. We also tested the reduction with the Hantzsch ester known for its high degree of stereo-control in the reduction of $\alpha, \beta$-unsaturated carbonyl compounds, cyclic/acyclic imines and activated olefins. ${ }^{44}$ Experimental tests for the asymmetric hydrogenation of $\mathbf{1 b}$ with the Hantzsch ester mediated by L-proline in apolar solvent at room temperature as well as at $60{ }^{\circ} \mathrm{C}$ resulted in no formation of the expected hydrogenated product. Overall the asymmetric hydrogenation of the disubstituted VBP substrates turned out to be an open challenge $e^{45,46}$ due to the high steric hindrance present on the $\mathrm{C}=\mathrm{C}$ double bond and its electron poor character.

\section{$\mathrm{Cu}$ (II)-Catalyzed addition of aryl boronic acids to substituted VBP}

In order to investigate the synthesis of more elaborated BP products, we tested the asymmetric addition of aryl boronic acids to $\beta$-disubstituted VBP in the presence of $\mathrm{Cu}$ (II) as the catalyst with the aid of chiral $\mathrm{N}$ based bidentate ligands (Scheme 6).

The desired product was not obtained even upon using the highly electrophilic bis-substituted substrate 1k in combination with the chiral bis(oxazoline) ligands (+)-2,2'-isopropylidenebis[(4R)-4-benzyl-2-oxazoline] (Box) and 2,6-bis[(4S)-(-)-isopropyl-2-oxazolin-2-yl]pyridine (PyBox), following the results recently reported for the asymmetric $\mathrm{Cu}$ (II) catalyzed 1,4-addition of phenyl boronate to electron deficient olefins. ${ }^{47}$ Differently, the Rh(I) catalyzed addition led to some reactivity, but only caused elimination of a phosphonate group from the BP reagent, regardless of the electron-withdrawing or electron-donating properties of the aryl-boronic acid being employed. The reaction did not proceed even in the absence of the chiral ligands probably due to the high steric hindrance present on the electrophilic $\beta-\mathrm{C}$ atom.

The reaction was then extended to the less hindered $\beta$-monosubstituted VBP 1a showing that product formation was largely influenced by the size of the boronic reagent. $\mathrm{Cu}(\mathrm{II})$ addition of phenylboronic acid to 1a did not lead to the desired product, but the use of a less hindered reagent like 3-thienyl boronic acid led to the corresponding addition product in excellent yield (Scheme 7). Alkyl boronic acids such as isopropyl boronic acid led only to the decomposition of 1a by loss of a phosphonate moiety.

Fig. 3 shows a comparison between the ${ }^{1} \mathrm{H}(\mathrm{A})$ and ${ }^{1} \mathrm{H}\left\{{ }^{31} \mathrm{P}\right\}$ (B) NMR spectra of $\mathbf{3 a}$ showing the simplification of the resonance peaks in the latter spectrum. The ${ }^{31} \mathrm{P}\left\{{ }^{1} \mathrm{H}\right\}-\mathrm{NMR}$ spectrum of $\mathbf{3 a}$ showed the formation of two doublets typically downfield shifted

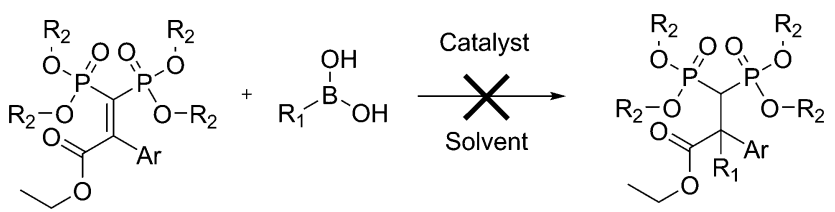

Scheme 6 Asymmetric addition of boronic acids to $\beta$-bis-substituted VBP.

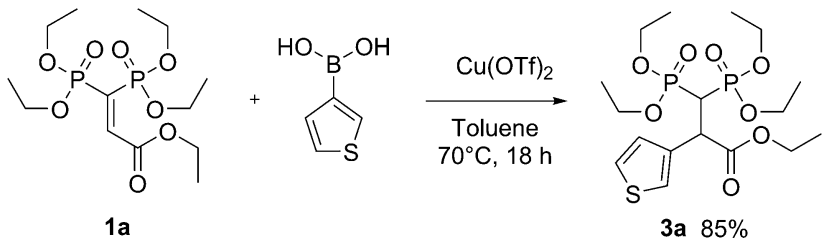

Scheme 7 Addition of 3-thienylboronic acid to 1a leading to the corresponding addition product $3 \mathbf{a}$.

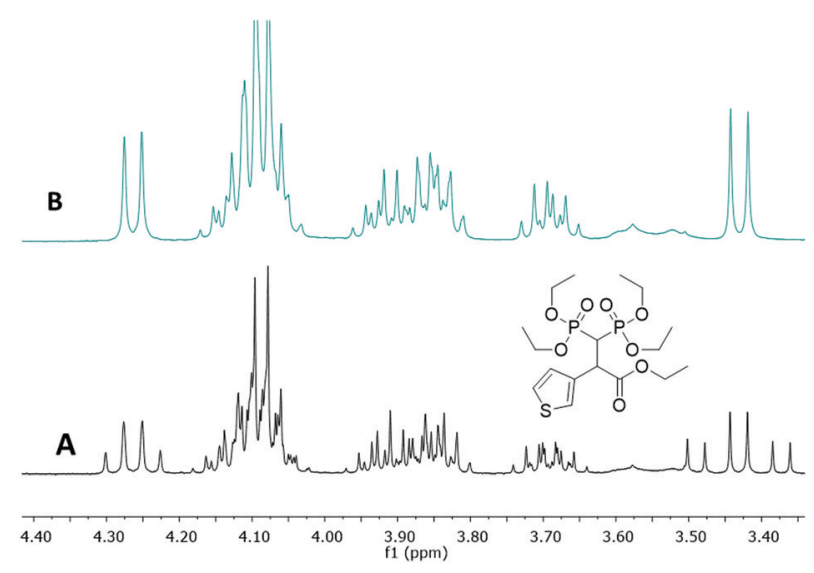

Fig. 3 (A) ${ }^{1} \mathrm{H}-\mathrm{NMR}$ and $(\mathrm{B}){ }^{1} \mathrm{H}\left\{{ }^{31} \mathrm{P}\right\}-\mathrm{NMR}$ of $3 a$

with respect to the resonances of reagent $\mathbf{1 a}$ as commonly observed for addition products on VBP and characterized by a much smaller $J_{\mathrm{P}-\mathrm{P}}$ coupling constant of $2.4 \mathrm{~Hz}$ (see the ESI $\dagger$ ). Attempts to induce asymmetry in the reaction using Box and PyBox as chiral ligands turned out to be inefficient forming only racemic product $\mathbf{3 a}$.

\section{Friedel-Crafts reaction between indoles and 1a}

Several attempts were made to investigate the asymmetric version of the Friedel-Crafts reaction between indoles and the substituted bisphosphonate precursors (Scheme 8) characterized by different electronic properties under the above optimized catalytic conditions.

Tests on $\mathbf{1 b}$ and the electron-poor $\mathbf{1 k}$ precursors were performed with free $\mathrm{Cu}(\mathrm{OTf})_{2}$ as well as in the presence of chiral ligands such as (+)-2,2'-isopropylidenebis[(4R)-4-benzyl-2-oxazoline] (Box) and 2,6bis[(4S)-(-)-isopropyl-2-oxazolin-2-yl]pyridine (PyBox) but unfortunately no evidence of product formation was obtained, recovering in both cases only the unconverted prochiral bisphosphonate reagent. The lack of reactivity is probably due to the intrinsic steric

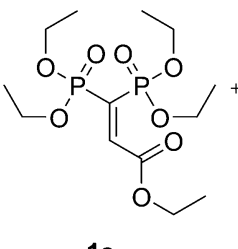

$1 \mathbf{a}$

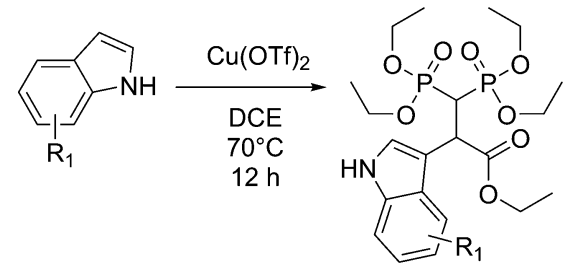

4aa-4ah
Scheme 8 General Friedel-Crafts reaction of indole substrates to $\mathbf{1 a}$ 
Table 3 Addition of indoles to substituted VBP precursor 1a mediated by $\mathrm{Cu}(\mathrm{OTf})_{2}$

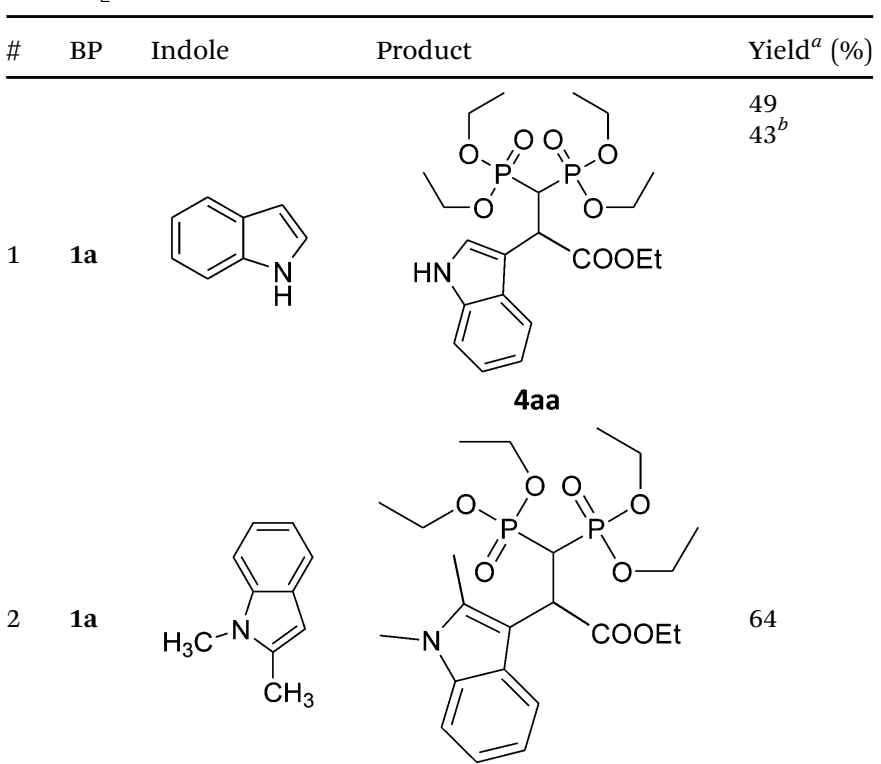

1a<smiles>Cn1ccc2ccccc21</smiles><smiles>Cc1c(Br)ccc2cc[nH]c12</smiles><smiles>COC(=O)c1ccc2[nH]ccc2c1</smiles>

$4 a b$<smiles>CCOC(=O)C(c1cn(C)c2ccccc12)C(C(C(=O)OCC)P(=O)(OCC)OCC)P(=O)(OCC)OCC</smiles>

$4 a c$<smiles>CCOC(=O)C(c1c[nH]c2c(C)c(Br)ccc12)C(P(=O)(OCC)OCC)P(=O)(OCC)OCC</smiles>

4ad<smiles>CCOC(=O)C(c1c[nH]c2ccc(C(=O)OC)cc12)C(C(C(=O)OCC)P(=O)(OCC)OCC)P(=O)(OCC)OCC</smiles><smiles>CCOC(=O)C(c1c(-c2ccccc2)[nH]c2ccccc12)C(C(C(=O)OCC)P(=O)(OCC)OCC)P(=O)(OCC)OCC</smiles>

Table 3 (continued)

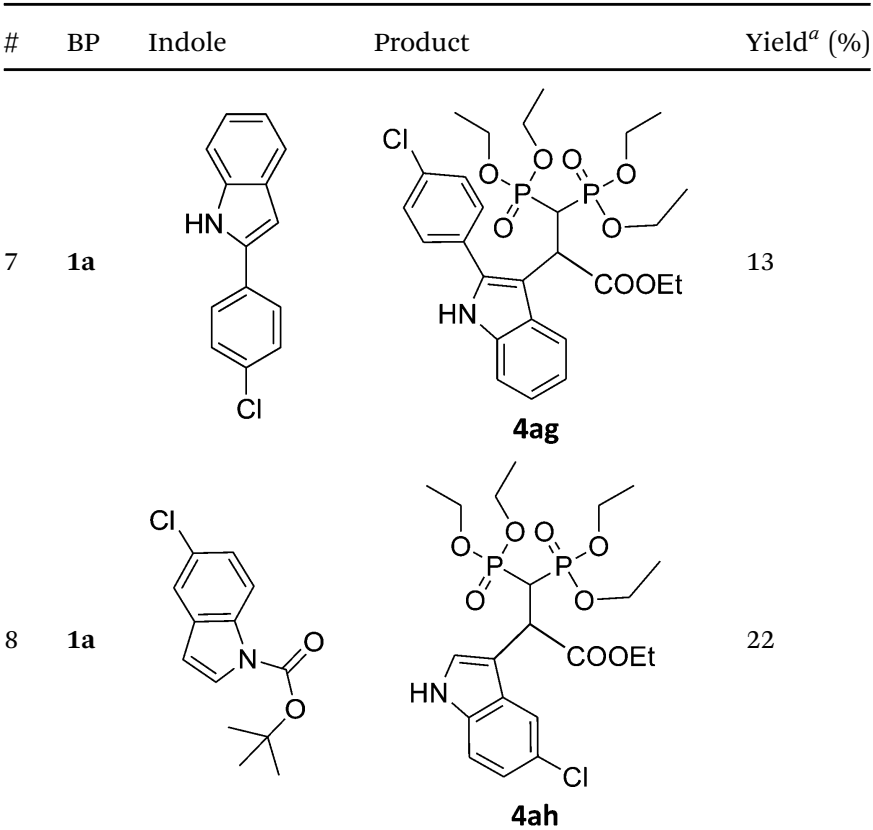

Reaction conditions: $1 \mathrm{mmol}$ monosubstituted VBP, $1.5 \mathrm{mmol}$ indole, $10 \mathrm{~mol} \% \mathrm{Cu}(\mathrm{OTf})_{2}$ in DCE, $T=70{ }^{\circ} \mathrm{C}, t=12 \mathrm{~h}^{a}{ }^{a}$ Isolated yield. ${ }^{b}$ [SDS] $=$ $100 \mathrm{mM}$ in water at $70{ }^{\circ} \mathrm{C}$.

hindrance present at the $\beta$-position of the aromatic substituted BP precursors.

The addition of indole to the less sterically hindered substrate 1a confirmed the formulated hypothesis observing the reaction at position 3 of the indole unit. It is also worth noting that, as previously reported for the addition of indoles to VBP, the reaction could be carried out also in aqueous micellar media (Table 3, entry 8) obtaining yields similar to those obtained in DCE as organic solvent. 1a was then reacted with a wide range of indoles with different electronic and steric properties applying the optimized catalytic system (Table 3, entries 1-8). In general the presence of electron-donating groups as substituents in the nitrogen containing five-membered ring of indole led to higher reaction yields (Table 3, entries 2 and 3) compared to the presence of electron withdrawing groups on the six-membered ring (Table 3, entries 4 and 5). Moreover, with sterically hindered indoles containing phenyl substituents, a lowering of the reaction yields was observed (Table 3, entries 6 and 7). With 1-(tert-butoxycarbonyl)-5-chloroindole (Table 3, entry 8) partial loss of the tert-butoxycarbonyl group occurred during the reaction, leading to a completely deprotected product after chromatographic purification, presumably because of the acid character of silica. The results were confirmed by EI-MS analysis and ${ }^{1} \mathrm{H}$ NMR which showed the presence of signals typical of the indolyl nitrogen proton. Comparing the results for the addition of indoles to 1a with those previously reported for the reaction on $\mathrm{VBP},{ }^{22}$ generally lower yields were observed most likely due to steric effects at the $\beta$-position. In Fig. 4 the ${ }^{31} \mathrm{P}$ $\left\{{ }^{1} \mathrm{H}\right\}$-NMR spectrum of 4aa shows two doublets with a really small coupling constant $(J=2.4 \mathrm{~Hz})$ downfield shifted compared to $1 \mathrm{a}$. 


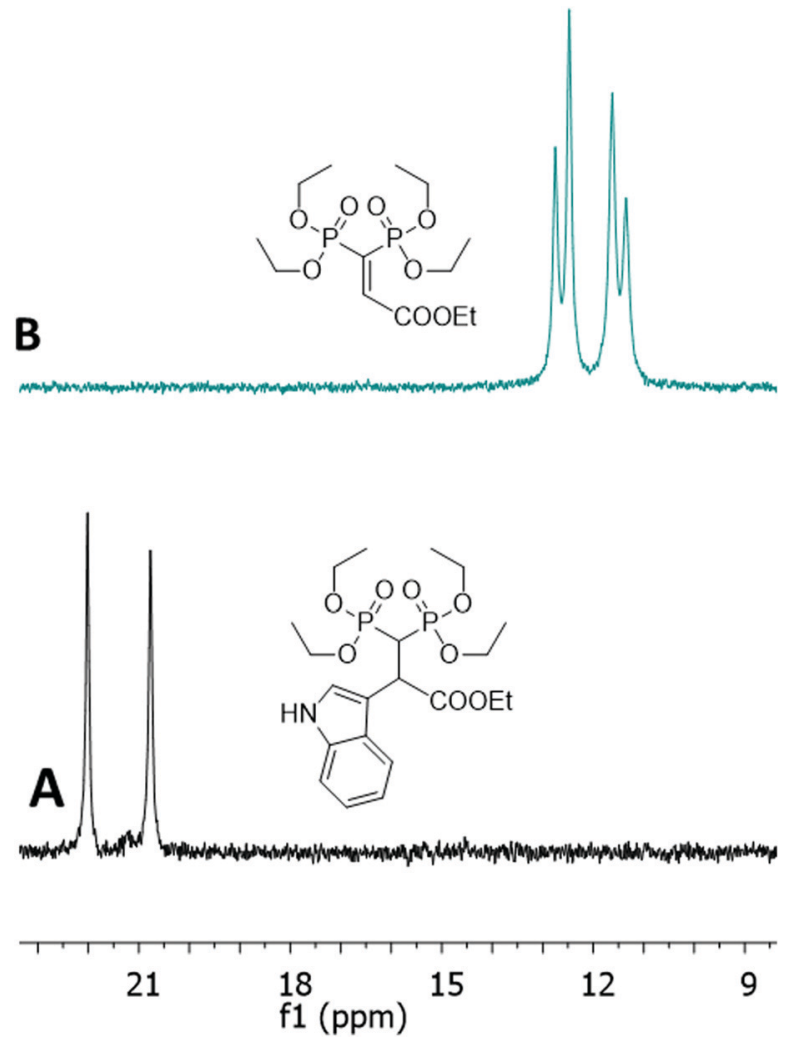

Fig. 4 (A) ${ }^{31} \mathrm{P}\left\{{ }^{1} \mathrm{H}\right\}-N M R$ of $4 \mathrm{aa}$ and $(B){ }^{31} \mathrm{P}\left\{{ }^{1} \mathrm{H}\right\}-\mathrm{NMR}$ of $1 \mathrm{a}$.

\section{Deprotection of the phosphoric ester moiety}

In order to obtain the final version of the BP products with free phosphonic acid units, some of the newly synthesized products, 1a, 2b and the indolyl-containing BP products 4aa were deprotected with trimethylsilyl bromide following an improved procedure compared to that reported in the literature. ${ }^{20}$ The corresponding deprotected bisphosphonic acids $\mathbf{5 a}, \mathbf{5 b}$ and $\mathbf{5 a a}$ were isolated in quantitative yields and characterized by ${ }^{1} \mathrm{H}$ and ${ }^{31} \mathrm{P}$-NMR spectroscopy in $\mathrm{D}_{2} \mathrm{O}$. In particular, the acids bearing aromatic units showed surfactant like properties due to their amphiphilic nature, as confirmed by the appearance of broad resonances in the ${ }^{31} \mathrm{P}$ NMR spectra (see the ESI $\dagger$ ). Further detailed biological evaluation on osteoclast bone cell activity will be carried out in order to investigate the anti-resorption properties of the new classes of BPs synthesized in the present work.

\section{Conclusions}

In conclusion, herein we reported about the synthesis of a new class of prochiral $\beta$-mono-substituted and $\beta$-bis-substituted vinylidenebisphosphonate esters $\mathbf{1 a - k}$ as building blocks for further functionalizations to widen the range of structures for the preparation of bisphosphonic acids as potential leads to contrast osteoporosis and bone related diseases. Further functionalization through metal mediated addition of aryl boronic acids and indoles on 1a led to the formation of new BPs bearing heterocyclic units at the $\beta$ position. Conversely, the addition reactions on bis-substituted vinylidenebisphosphonate 1b-k turned out to be hampered by steric interactions, while hydrogenation of $\mathbf{1 b}-\mathbf{l}$ produced a large series of racemic products 2b-1. Further deprotection of the phosphoric ethyl ester units resulted in free BPs characterized by solubility in water and some surfactant like properties due to their amphiphilic nature.

\section{Conflicts of interest}

There are no conflicts to declare.

\section{Acknowledgements}

The authors acknowledge Università Ca' Foscari Venezia and MIUR for support.

\section{Notes and references}

1 S. Zhang, G. Gangal and H. Uludağ, Chem. Soc. Rev., 2007, 36, 507-531.

2 R. Graham and G. Russell, Bone, 2011, 49, 2-19.

3 F. H. Ebetino, A.-M. L. Hogan, S. Sun, M. K. Tsoumpra, X. Duan, J. T. Triffitt, A. A. Kwaasi, J. E. Dunford, B. L. Barnett, U. Oppermann, M. W. Lundy, A. Boyde, B. A. Kashemirov, C. E. McKenna and R. G. G. Russell, Bone, 2011, 49, 20-33.

4 M. J. Rogers, J. C. Crockett, F. P. Coxon and J. Mönkkönen, Bone, 2011, 49, 34-41.

5 Y. Zhang, R. Cao, F. Yin, M. P. Hudock, R.-T. Guo, K. Krysiak, S. Mukherjee, Y.-G. Gao, H. Robinson, Y. Song, J. H. No, K. Bergan, A. Leon, L. Cass, A. Goddard, T.-K. Chang, F.-Y. Lin, E. Van Beek, S. Papapoulos, A. H.-J. Wang, T. Kubo, M. Ochi, D. Mukkamala and E. Oldfield, J. Am. Chem. Soc., 2009, 131, 5153-5162.

6 A. J. Wiemer, J. S. Yu, L. W. Shull, R. J. Barney, B. M. Wasko, K. M. Lamb, R. J. Hohl and D. F. Wiemer, Bioorg. Med. Chem., 2008, 16, 3652-3660.

7 A. G. Roth, D. Drescher, Y. Yang, S. Redmer, S. Uhlig and C. Arenz, Angew. Chem., Int. Ed., 2009, 48, 7560-7563.

8 Y. Zhang, R. Cao, F. Yin, F.-Y. Lin, H. Wang, K. Krysiak, J.-H. No, D. Mukkamala, K. Houlihan, J. Li, C. T. Morita and E. Oldfield, Angew. Chem., Int. Ed., 2010, 49, 1136-1138.

9 J. H. No, F. de Macedo Dossin, Y. Zhang, Y.-L. liu, W. Zhu, X. Feng, J. Anny Yoo, E. Lee, K. Wang, R. Hui, L. H. FreitasJunior and E. Oldfield, Proc. Natl. Acad. Sci. U. S. A., 2012, 109, 4058-4063.

10 (a) M. Capuzzi, D. Perdicchia and K. A. Jørgensen, Chem. Eur. J., 2008, 14, 128-135; (b) S. Sulzer-Mossè, M. Tissot and A. Alexakis, Org. Lett., 2007, 9, 3749-3752; (c) M. T. Barros and A. M. Faisca Phillips, Eur. J. Org. Chem., 2008, 2525-2529.

11 F. H. Ebetino, J. E. Dunford, M. W. Lundy, M. Pozzi, Z. Xia, R. Dobson, M. Quijano, R. Christian, B. A. Kashemirov, 
C. E. McKenna, G. G. Russell and B. L. Barnett, Bone, 2008, 42, S36-S37.

12 G. R. Kieczykowski, R. B. Jobson, D. G. Mellilo, D. F. Reinhold, V. J. Grenda and I. Shinkai, J. Org. Chem., 1995, 60, 8310-8312.

13 M. Egorov, S. Aoun, M. Padrines, F. Redini, D. Heymann, J. Lebreton and M. Mathé-Allainmat, Eur. J. Org. Chem., 2011, 7148-7154.

14 R. L. McConnell and H. W. Coower, J. Am. Chem. Soc., 1956, 78, 4450-4452.

15 R. A. Nugent, M. Murphy, S. T. Schlachter, C. J. Dunn, R. J. Smith, N. D. Staite, L. A. Galinet, S. K. Shields, D. G. Aspar, K. A. Richard and N. A. Rohloff, J. Med. Chem., 1993, 36, 134-139.

16 D. Granchi, A. Scarso, G. Bianchini, A. Chiminazzo, A. Minto, P. Sgarbossa, R. A. Michelin, G. Di Pompo, S. Avnet and G. Strukul, Eur. J. Med. Chem., 2013, 65, 448-455.

17 D. Simoni, N. Gebia, F. P. Invidiata, M. Eleopra, P. Marchetti, R. Rondanin, R. Baruchello, S. Provera, C. Marchioro, M. Tolomeo, L. Marinelli, V. Limongelli, E. Noveliono, A. Kwaasi, J. Dunford, S. Buccheri, N. Cacamo and F. Dieli, J. Med. Chem., 2008, 51, 6800-6807.

18 M. Ferrer-Casal, A. P. Barboza, S. H. Szajnman and J. B. Rodriguez, Synthesis, 2013, 2397-2404.

19 R. Ruziconi, G. Rici, A. Gioiello, H. Couthon-Gourvès and J.-P. Gourvès, J. Org. Chem., 2003, 68, 736-742.

20 O. Bortolini, I. Mulani, A. De Nino, L. Maiuolo, M. Nardi, B. Russo and S. Avnet, Tetrahedron, 2011, 67, 5635-5641.

21 P. C. B. Page, M. J. McKenzie and J. A. Galagher, J. Org. Chem., 2001, 66, 3704-3708.

22 A. Chiminazzo, L. Sperni, M. Damuzzo, G. Strukul and A. Scarso, ChemCatChem, 2014, 6, 2712-2718.

23 G. Bianchini, A. Scarso, A. Chiminazzo, L. Sperni and G. Strukul, Green Chem., 2013, 15, 656-662.

24 (a) L. De Luca, A. Chiminazzo, L. Sperni, G. Strukul and A. Scarso, Chem. - Eur. J., 2017, 23, 3474-3478; (b) A. Chiminazzo, L. Sperni, A. Scarso and G. Strukul, Catalysts, 2017, 7, 90; (c) L. De Luca, A. Chiminazzo, L. Sperni, G. Strukul and A. Scarso, ChemistrySelect, 2017, 2, 3262-3267; (d) A. Chiminazzo, M. Damuzzo, L. Sperni, G. Strukul and A. Scarso, Helv. Chim. Acta, 2017, 100, e1700104.

25 A. Chiminazzo, G. Borsato, A. Favero, C. Fabbro, C. E. McKenna, L. G. Dalle Carbonare, M. T. Valenti, F. Fabris and A. Scarso, Chem. - Eur. J., 2019, 25, 3617-3626.

26 D. Villemin, F. Thibault-Starzyk and E. Esprimont, Phosphorus, Sulfur Silicon Relat. Elem., 1992, 70, 117-120.
27 A. Köckritz and M. Schnell, Phosphorus, Sulfur Silicon Relat. Elem., 1992, 73, 185-194.

28 W. M. Abdou, N. A. Ganoub, A. F. Fahmy and A. A. Shaddy, Monatsh. Chem., 2006, 137, 105-116.

29 H. Xiang, J. Qi, Q. He, M. Jiang, C. Yang and L. Denga, Org. Biomol. Chem., 2014, 12, 4633-4636.

30 W. M. Abdou, A. A. Kamel and M. D. Khidre, J. Heterocycl. Chem., 2015, 52, 1654-1662.

31 S. Pei, C. Xue, L. Hai and Y. Wu, RSC Adv., 2014, 4, 38055-38058.

32 Y. Jie, L. Nan, C. Dian-Feng and L. Shi-Wei, Tetrahedron Lett., 2014, 55, 2859-2864.

33 (a) Z.-Y. Xue, Q.-H. Li, H.-Y. Tao and C.-J. Wang, J. Am. Chem. Soc., 2011, 133, 11757-11765; (b) S. Manda, A. Wani, S. S. Bharate, R. A. Vishwakarma, A. Kumar and S. B. Bharate, Med. Chem. Commun., 2016, 7, 1910-1915; (c) J. Huang, M.-X. Zhao and W.-L. Duan, Tetrahedron Lett., 2014, 55, 629-631; (d) C.-A. Chen and J.-M. Fang, Org. Biomol. Chem., 2013, 11, 7687-7699.

34 S. M. Nicolle and C. J. Moody, Chem. - Eur. J., 2014, 20, 4420-4425.

35 X. Creary, J. Org. Chem., 1987, 52, 5026-5030.

36 G. Knobloch, N. Jabari, S. Stadlbauer and A. Gohla, Bioorg. Med. Chem., 2015, 23, 2819-2827.

37 H. Ding, G. Xu, J. Wang, Y. Zhang, X. Wu and Y. Xie, Heteroat. Chem., 2004, 15, 549-555.

38 C. Chen and J. M. Fang, Org. Biomol. Chem., 2013, 11, 7687-7699.

39 H. Xiang, X. Qi, Y. Xie, G. Xu and C. Yang, Org. Biomol. Chem., 2012, 10, 7730-7738.

40 P. Etayo and A. Vidal-Ferran, Chem. Soc. Rev., 2013, 42, 728-754.

41 P. Kleman and A. Pizzano, Tetrahedron Lett., 2015, 56, 6944-6963.

42 Y. Xi and X. Shi, Chem. Commun., 2013, 49, 8583-8585.

43 H. Xie, A. Song, X. Zhang, X. Chen, H. Li, C. Sheng and W. Wang, Chem. Commun., 2013, 49, 928-930.

44 S. G. Ouellet, A. M. Walji and D. W. C. MacMillan, Acc. Chem. Res., 2007, 40, 1327-1339.

45 M. Zhang, L. Chen, Y. You, Z. Wang, D. Yue, X. Zhang, X. Xu and W. Yuan, Tetrahedron, 2016, 72, 2677-2682.

46 L. C. Morrill, L. A. Ledingham, J. P. Couturier, J. Bickel, A. D. Harper, C. Fallan and A. D. Smith, Org. Biomol. Chem., 2014, 12, 624-636.

47 K. Takatsu, R. Shintani and T. Hayashi, Angew. Chem., Int. Ed., 2011, 50, 5548-5552. 